\title{
ANÁLISE DA DINÂMICA ESPACIAL DA OCUPAÇÃO ANTRÓPICA EM PARANAGUÁ/PR (1952-1996), ATRAVÉS DO USO DE SISTEMA DE INFORMAÇÕES GEOGRÁFICAS
} Spatial dynamic analysis of antropic occupation in Paranaguá-PR (1952-1996), through the geographical information use

\author{
Sony Cortese CANEPARO'
}

\begin{abstract}
RESUMO
Este trabalho estuda a dinâmica espacial da ocupação antrópica no perímetro urbano de Paranaguá, Paraná (Brasil), nos anos de 1952, 1962, 1980 e 1996. A metodologia aplicada fundamenta-se na utilização do sistema de informação geográfica, aliado ao sensoriamento remoto. Foram geradas séries temporais de planos de informações (tipos de cobertura vegetal e categorias de uso da terra), os quais foram cruzados, para acompanhar a evolução da mancha urbana. Observações de campo e levantamentos bibliográficos foram necessários para o apoio à compreensão dessa dinâmica. Detectou-se uma forte dinâmica espacial da ocupação antrópica no perímetro urbano de Paranaguá; entre 1952 e 1996, a área antropizada foi de 2.269 ha. Tal antropização ocorreu a partir do centro da cidade em direção ao porto e nas margens dos rios que a banham; é decorrente principalmente dos ciclos econômicos ligados ao setor portuário, à migração, ao crescimento natural da população e ao acesso às praias.

Palavras-chave: sistema de informações geográficas, SIG, sensoriamento remoto, dinâmica espacial urbana, meio ambiente.
\end{abstract}

\begin{abstract}
This study covers the spatial dynamics of anthropic occupation in the urban area of Paranaguá, Paraná, Brazil, in the years 1952, 1962, 1980, and 1996. The methodology applied was based on GIS (Geographical Information System) associated to remote sensing. Temporal series of

1 Geógrafa Doutora em Meio Ambiente e Desenvolvimento. Professora do Departamento de Geografia da Universidade Federal do Paraná.
\end{abstract}


information plans were generated (types of vegetation and land use categories), and the information therefore were crossed in order to observe the evolution of the urban sprawl. Field observation and bibliographic surveys were required to support the understanding of such dynamics. It was found strong spatial dynamics of anthropic occupation in the urban area of Paranaguá; between 1952 and 1996, the area occupied was 2.269 ha. This anthropization occured from downtown to the port and at hedge of the rives; due to the economic fases of the port, to the migration, to the natural population increase and the roads to the beaches.

Key-words: geographic information systems, GIS, remote sensing, urban spatial dynamics, environment.

\section{INTRODUÇÃO}

O sensoriamento remoto e o sistema de informação geográfica na atualidade são ferramentas imprescindíveis nos estudos urbanos, que levem em consideração a dinâmica têmporo-espacial.

Estudos que pontuem o crescimento e a dinâmica espacial em áreas urbanas tornam-se cada vez mais necessários, uma vez que refletem as tendências de crescimento natural ou não da cidade, auxiliando os seus planejadores.

Pesquisas realizadas na cidade de Paranaguá demonstraram que ela tem apresentado um acentuado crescimento espacial decorrente principalmente dos ciclos econômicos pelos quais passou e passa o Brasil, o Estado do Paraná e o Porto de Paranaguá (Porto D. Pedro II). Este crescimento tem gerado algumas situações de tensão na cidade, tais como: ocupação de áreas de proteção permanente, saneamento básico ineficiente, problemas de prestação de serviços (escolas, sistema viário e assistência à saúde), degradação ambiental e problemas sociais (COSTA et al., 1999, p. 41-46; GODOY, 1998, p. 1-230).

Paranaguá está localizada na planície litorânea do Estado do Paraná, é entremeada por diversos rios e possui duas coberturas vegetais predominantes: a restinga e o manguezal. Aí está localizado o maior porto em exportação e importação do Estado do Paraná, o Porto D. Pedro II. É escala obrigatória das rotas internacionais de mercado e possui uma área de abrangência que envolve os Estados do Paraná, sul de São Paulo, Santa Catarina, norte do Rio Grande do Sul, Mato Grosso do Sul e Paraguai (PARANAGUÁ, 1994, p.10-19).

Diante dessas constatações, esta pesquisa objetiva estudar a dinâmica espacial da ocupação antrópica no perímetro urbano de 
Paranaguá. Para tal, lançou-se mão dos produtos do sensoriamento remoto aliado ao sistema de informação geográfica, o qual requer o estabelecimento prévio de variáveis que sirvam de indicadores para avaliar o processo das transformações do espaço num período definido. As variáveis utilizadas que possibilitaram a avaliação e tendências dessa dinâmica foram: tipos de cobertura vegetal (1952, 1962, 1980 e 1996) e uso da terra.

\section{CARACTERIZAÇÃO DO PERÍMETRO URBANO DE PARANAGUÁ}

\section{SITUAÇÃO GEOGRÁFICA}

A área de estudo está localizada no município de Paranaguá, litoral do Estado do Paraná, entre os paralelos $25^{\circ} 30^{\prime}$ e $25^{\circ} 41^{\prime}$ de latitude sul e os meridianos 48 $24^{\prime}$ 'a 48 $37^{\circ}$ ' de longitude oeste de Greenwich. Ocupa 14.269 hectares, abrangendo o perímetro urbano de Paranaguá, criado através da Lei Complementar n 01/93, aprovada em 20/01/993 e alterado através da Lei n 11.252 de 20/12/95.

\section{ASPECTOS FÍSICOS}

De acordo com a Comissão da Carta Geológica do Paraná (RIVERAU et al., 1968), o perímetro urbano do município de Paranaguá é constituído pelas unidades geológicas: $M$ - áreas de manguezais, localizadas nas bordas dos rios e das ilhas presentes. Coincidem com as áreas onde predomina o ecossistema manguezal e são de idade recente, ou seja, do Quaternário; $Q p$ - áreas denominadas "praias atuais", do Quaternário, sendo que na área de estudo, este tipo geológico está presente predominantemente na ilha da Cotinga; Qa2 - tratam-se de áreas constituídas por aluviões indiferenciados recentes do Quaternário. Na região em questão, os aluviões mais recentes estão presentes na parte sul, num trecho próximo à PR-407 (estrada das Praias) e margeando o rio Guaraguaçu; Qa1 - tratam-se de áreas constituídas por aluviões indiferenciados antigos do Quaternário. $\mathrm{Na}$ região em questão, os aluviões mais antigos estão presentes na sua parte sul, num trecho próximo à PR-407 (estrada das Praias) e ao rio Guaraguaçu. Margeando este rio, encontram-se pequenas áreas em que estes aluviões são mais recentes; $Q b$ - áreas constituídas por 
sedimentos areno-síltico-argilosos de baía, datados do Quaternário, presentes em algumas regiões localizadas na ilha do Curral, nas margens dos rios Itiberê, dos Correias, dos Almeidas, Guaraguaçu, e ainda nas ilhas dos Valadares, Cotinga e Rasa da Cotinga; Qm sedimentos arenosos indiferenciados de origem marinha do Quaternário, de fase mais antiga. Ocupam uma parte significativa da planície de restinga e da ilha Rasa da Cotinga, inclusive da cidade de Paranaguá. Nestas áreas, segundo o autor, predominam muitos cordões de praia antigos, alguns meandros antigos e outras feições lineares do Quaternário; Diques de diabásio - constituem-se em diques de diorito pórfiro, de idade Jurássico-Cretáceo, localizados na ilha da Cotinga; pEm - são regiões de morros isolados constituídas por migmatitos heterogêneos (epibolitos) associados a embrechitos (dent du cheval), localmente cortados por pegmatitos e aplo-granitos, datados do PréCambriano. Na área de estudo, correspondem aos morros isolados situados ao norte do perímetro urbano de Paranaguá e na ilha da Cotinga (porção oeste).

Quanto ao aspecto geomorfológico, a área de estudo está inserida no litoral paranaense, o qual é dividido, segundo MAACK (1968, p. 86), em duas sub-regiões geográficas naturais, quais sejam, a montanhosa litorânea e a planície litorânea. Em estudos mais recentes, OKA-FIORI e CANALI (1998, p. 52-55) dividem o litoral paranaense em três compartimentos geomorfológicos: compartimento das serras e morros, compartimento das planícies e compartimento dos mangues.

O primeiro compartimento está representado pelas serras do Cubatão, da Araraquara e Grande no município de Guaratuba, pelas serras do Engenho e da Prata, nos municípios de Matinhos de Paranaguá, e ao norte pela serra do Feiticeiro, no limite de Paranaguá com Guaraqueçaba. Neste compartimento, o relevo é acidentado, com desníveis que podem alcançar 1.800 metros, e as declividades são geralmente superiores a 45․ Quanto à litologia, aparecem aí os granitos intrusivos e migmatitos (OKA-FIORI; CANALI, p. 52-53).

O compartimento das planícies, também denominado de planície costeira, divide-se em planícies aluviais e de restinga. As planícies aluviais foram originadas de depósito de sedimentos de origem fluvial, quando grande parte da plataforma continental ficava emersa, sendo sulcada pelos rios, gerando um novo nível de base durante os períodos de mar baixo. As planícies de restinga formaram-se depois de uma transgressão marinha, quando o nível do mar começa a descer, possibilitando a deposição de sedimentos junto à linha de costa, formando os cordões arenosos litorâneos. Na área em estudo, os 
cordões litorâneos localizam-se ao sul da baía de Paranaguá, em forma triangular, desde a serra da Prata até o oceano Atlântico (OKA-FIORI; CANALI, 1998, p. 53-54; ANGULO, 1992, p. 299-302).

Quanto ao compartimento dos mangues, localiza-se beirando a baía de Paranaguá. São locais alagadiços e pantanosos, sujeitos ao fluxo e refluxo das marés; o solo é extremamente salino (OKA-FIORI; CANALI, 1998, p. 54).

Os rios do litoral do Estado do Paraná pertencem à bacia hidrográfica Atlântica (BIGARELLA et al., 1978, p. 25). No perímetro urbano de Paranaguá localizam-se vários cursos d'água que têm suas nascentes na Serra do Mar e correm na direção sudoeste-nordeste, desaguando diretamente na baía de Paranaguá, destacando-se: o rio Embocuí, localizado na porção noroeste do perímetro urbano, entre a ilha do Curral e o continente, o rio Emboguaçu- Mirim e Emboguaçu (banha a cidade na sua porção oeste), o rio Itiberê (banha a cidade de Paranaguá na sua parte sul e leste, separa a cidade da ilha dos Valadares), o rio dos Correias (banha a porção sul, sudeste e leste da ilha dos Valadares), e os rios mais distantes da cidade: rio dos Almeidas, Pequeno e Guaraguaçu (limite leste da área em estudo). Nas ilhas da Cotinga e Rasa da Cotinga, correm alguns pequenos rios; na primeira, o mais expressivo é o rio Furado e na segunda, o rio do Cerco (CANEPARO, 1999, p. 101).

Segundo BIGARELLA et al. (1978, p. 45), Koeppen classifica o clima de Paranaguá como do tipo $\mathrm{Cfa}$, ou seja, subtropical úmido mesotérmico, com o mês mais frio de temperatura média inferior a $18^{\circ} \mathrm{C}$ (em Paranaguá, atinge $17^{\circ} \mathrm{C}$, no mês de julho) e superior a $-^{\circ}{ }^{\circ} \mathrm{C}$ e 0 mês mais quente com temperatura média superior a $22^{\circ} \mathrm{C}$ (em Paranaguá atinge 24,9ㄷ). Entretanto, MAACK (1968, p. 170-185) diz que predomina na área o tipo climático Af, da classificação de Koeppen, isto é, tropical, superúmido, com o mês mais frio possuindo temperatura média superior a $18^{\circ} \mathrm{C}$, sem estação seca e isento de geadas. Devido ao fato de Paranaguá possuir, no mês mais frio, uma temperatura média de $17^{\circ} \mathrm{C}$, esta classificação proposta por MAACK não se enquadra no conceito de Koeppen, cujo significado da letra "A" prevê temperatura média superior a $18^{\circ} \mathrm{C}$ para o mês mais frio (BIGARELLA et al., 1978, p. 45). O IAPAR (1994, p. 9-11; 21-44) classifica o clima de Paranaguá como Af, indo ao encontro da classificação proposta por MAACK.

De acordo com HENKLAIN (1994, p. 49-59), as classes de solos predominantes na área de estudo são: PV - Podzólico VermelhoAmarelo, estão situados em cotas mais elevadas e onde o relevo é mais movimentado. Na área em estudo, localizam-se na ilha da Cotinga; 
AQ1 - Areias Quartzosas Vermelho e Amarelas distróficas A moderado fase relevo praticamente plano (acentuadamente drenado). Estão localizadas na porção noroeste do perímetro urbano de Paranaguá; AQ2 - Associação de Areias Quartzosas Vermelhas e Amarelas distróficas (AQ1) + Podzol álico (P2). Essa unidade apresenta, além desses dois componentes, inclusões de pequenas manchas de Solos Aluviais. Localiza-se na ilha dos Valadares; P2- Podzol álico A moderado textura arenosa fase relevo plano (mal drenado e imperfeitamente drenado). Esses solos quando cultivados perdem o teor de matéria orgânica, ficando a areia exposta aos perigos da erosão, principalmente a erosão eólica, devido à falta de coesão de suas partículas. Devem ser mantidos em estado natural. Localizam-se nas proximidades da foz do rio Pequeno e Guaraguaçu e nas ilhas Rasa da Cotinga e do Curral; P3 - Associação Podzol Hidromórfico álico (P2) + Solos Orgânicos álicos (HO1). Localiza-se principalmente entre os rios Itiberê e dos Almeidas; P4 - Associação de Podzol álico (P2) + Glei pouco Húmico álico textura média fase relevo plano (imperfeitamente drenado). Na área de estudo, aparece em uma mancha nas proximidades da margem direita do rio dos Almeidas; P5 - Associação de Podzol álico (P2) + Podzol Hidromórfico álico (P1). É o tipo de solo de maior ocorrência no perímetro urbano de Paranaguá; HGP3 - Associação de Glei pouco Húmico Tiomórfico (HGP1) + Solos Aluviais distróficos (A1). Está localizado nas partes mais elevadas, coincidindo com os diques marginais dos rios, e abrange os $40 \%$ restantes da área.

Nessa pesquisa utilizou-se a divisão proposta por RODERJAN; KUNIYOSHI (1988, p. 1-4) e a do Manual técnico da vegetação brasileira (IBGE, 1992, p. 16-32), para se denominar as unidades de vegetação delimitadas na área de estudo. No perímetro urbano de Paranaguá, existem as seguintes unidades de vegetação: Floresta Ombrófila Densa das Terras Baixas - Restinga; Floresta Densa Ombrófila Submontana; Área de Formação Pioneira sob Influência Fluviomarinha - Manguezal; Área de Formação Pioneira sob Influência Fluviomarinha - Área de Transição e Área de Formação Pioneira sob Influência Fluvial. A categoria Floresta Ombrófila Densa está ligada a fatores climáticos tropicais de temperatura elevada, com médias anuais em torno de $25^{\circ} \mathrm{C}$ e de precipitação alta e bem distribuída ao longo do ano (IBGE, 1992, p. 16-18). Segundo o IBGE (1992, p. 30-31), as Áreas de Formações Pioneiras sob influência marinha e dos rios ou pela ação combinada de ambos, são formações vegetais que se instalam sobre áreas pedologicamente instáveis, devido às constantes deposições dos cursos d'água e ao redor de pântanos, lagunas e lagoas. As Áreas de Transição 
estão localizadas em sentido contrário, logo após os mangues ou em depressões justapostas às dunas praiais e em direção ao continente, possuem formações herbáceas (RODERJAN; KUNIYOSHI, 1988, p. 911). As Formações Pioneiras sob Influência Fluvial, segundo o IBGE (1992, p. 31), constituem as comunidades vegetais das planícies aluviais que refletem o efeito das cheias dos rios ou então das depressões alagáveis.

O PROCESSO DE URBANIZAÇÃO E DESENVOLVIMENTO ECONÔMICO DE PARANAGUÁ

Em 1617, chegava à região Gabriel de Lara. Interessado em faiscar ouro, juntou-se à família espanhola Peneda. Ambos fundaram, na ilha da Cotinga, um povoamento onde estariam protegidos contra possíveis ataques dos índios carijós (SANTOS, 1952, p. 31 e 70).

Considerando esse local impróprio para uma povoação, Gabriel de Lara transferiu a população para a margem esquerda do rio Itiberê, justamente pela fertilidade do terreno, por ter água e para que as embarcações ficassem mais protegidas e seguras dos inimigos e dos ventos. Passaram a navegar nos rios dos Almeidas, Correias e Guaraguaçu, até as suas nascentes. Nas margens destes, descobriram abundantes minas de ouro (SANTOS, 1952, p. 16-17 e p. 31). Esse fato contribuiu para o povoamento e Paranaguá tornou-se ponto de irradiação de bandeiras. Também foi construído um atracadouro com a denominação de Porto de Nossa Senhora do Rosário de Paranaguá. A partir daí, até a mudança definitiva do porto para a baía de Paranaguá (final do século XIX), nas margens do rio Itiberê foram construídos vários atracadouros e cais (TRAMUJAS, 1996, p. 56; MORGENSTERN, 1985, p. 1).

Em 1648 foi criada da Vila de Nossa Senhora do Rosário de Paranaguá (SANTOS, 1952, p. 26).

Foi somente no final do século XVII, em função do ciclo do ouro, que Paranaguá despontou como importante pólo litorâneo e foi se expandindo a partir das margens do rio Itiberê (TRAMUJAS, 1996, p. 24-25; p. 56-57).

Em 1841, Paranaguá foi elevada à categoria de vila e no ano seguinte, à categoria de cidade (SANTOS, 1952, p. 311; 316).

A situação do Porto da cidade de Paranaguá, que se localizava nas margens do rio Itiberê, era precária: acanhado, pouco profundo e 
sujeito ao contínuo assoreamento. Era necessário mudar a localização do porto. Num local denominado Enseada do Gato, nas margens da baía de Paranaguá, foi inaugurado o porto da cidade de Paranaguá, com o nome de Porto D. Pedro II, em 17 de março de 1935 (MORGENSTERN,1985, p. 5).

A partir da transferência definitiva do porto das margens do rio Itiberê para as margens da baía de Paranaguá e em decorrência da exportação de café, ocorreu uma ocupação mais intensa na região norte da cidade, principalmente na década de 1950. A cidade enfrentava problemas de infra-estrutura: precário serviço de energia elétrica, de telefones e deficiência nos serviços de transporte de passageiros. $O$ crescimento das atividades portuárias tornou Paranaguá pólo de atração de populações do campo e de outras localidades, resultando em desequilíbrios sociais e espaciais na cidade. O porto foi um forte organizador do espaço e da economia local, demandando o crescimento do setor urbano em atividades ligadas ao setor portuário, no comércio de bens e serviços (GODOY, 1998, p. 111-112).

No final dos anos 60 iniciou-se a crise do café, seu preço caiu no mercado internacional e o local de beneficiamento passou de Paranaguá para a zona cafeeira no norte do Estado. Este fato gerou desemprego na cidade. O café começou então a ser substituído pela soja e trigo, os quais receberam incentivos do governo federal. A partir de 1970, foram construídos armazéns nas imediações do porto, que foi ampliado e remodelado. Nesta atividade, a manipulação das cargas era realizada por máquinas que passaram a substituir a mão-de-obra, gerando com isso uma diminuição no nível do emprego, aumentado os problemas sociais na cidade, refletindo-se numa desorganização do espaço, bem como na ocupação de áreas insalubres, ou seja, sobre os manguezais (GODOY, 1998, p. 118-134).

O Paraná tornou-se o maior produtor de soja e o Porto de Paranaguá, o maior exportador. Tal fato gerou a necessidade da adaptação e ampliação das instalações portuárias. Foram instalados armazéns e silos para atender a demanda de grãos; assim, o espaço urbano foi ampliado e remodelado (GODOY, 1998, p. 137).

Nos anos 80 e 90, Paranaguá expandiu sua área urbana pelas margens da BR-277 e PR-407 (Estradas das Praias), com a abertura de loteamentos, ao longo do trinário BR-277/Avenida Bento Munhoz da Rocha/Estrada do Matadouro e a Criação do Distrito Industrial de Paranaguá. Também foi intensificada a ocupação irregular de áreas de proteção permanente, os manguezais, das margens dos rios Emboguaçu e Itiberê (COSTA et al., 1999, p. 21). 
No início dos anos 90, o governo federal começou a incentivar a política de privatização de organismos e instituições governamentais. Nesta época, a proposta governamental é a modernização do Porto de Paranaguá por intermédio da iniciativa privada, promovendo mudanças significativas na sua dinâmica interna, refletindo nas suas relações com a cidade. Assim, o porto, com a adoção de tecnologias dispensadoras de mão-de-obra menos qualificada, passa a desempenhar um papel à parte no contexto urbano, resultando em impactos socioambientais negativos (desemprego, crescimento do setor informal, ocupação do espaço público e preservado por leis, entre outros) (TRAMUJAS, 1996, p. 149-150; GODOY, 1998, p. 233-234).

\section{ASPECTOS POPULACIONAIS DE PARANAGUÁ}

A cidade de Paranaguá ao longo do período de 1950 a 1996 apresentou uma população predominantemente urbana, sendo que o ano de 1980 é o de maior representatividade, com 89\% de população urbana (tabela 1).

TABELA 1 - POPULAÇÃO URBANA, RURAL E TOTAL DA CIDADE DE PARANAGUÁ(1) - 1950-1996

\begin{tabular}{|c|c|c|c|c|c|}
\hline \multirow{3}{*}{ ANO } & \multicolumn{5}{|c|}{ POPULAÇÃO } \\
\hline & \multicolumn{2}{|c|}{ Urbana } & \multicolumn{2}{|l|}{ Rural } & \multirow[b]{2}{*}{ TOTAL } \\
\hline & Abs. & $\%$ & Abs. & $\%$ & \\
\hline 1950 & 15803 & 68 & 7571 & 32 & 23374 \\
\hline 1960 & 27728 & 81 & 6335 & 19 & 34063 \\
\hline 1970 & 51462 & 85 & 9035 & 15 & 60497 \\
\hline 1980 & 71107 & 89 & 8364 & 11 & 79471 \\
\hline 1991 & 88163 & 88 & 11336 & 12 & 99499 \\
\hline 1996 & 108032 & 87 & 16888 & 13 & 124920 \\
\hline
\end{tabular}

FONTE: IBGE, Censos Demográficos de 1950, 1960, 1970, 1980, 1991, 1996

(1) Dados somente de cidade, sem os distritos.

A partir da década de 1960, Paranaguá passa a ser um pólo de atração econômico-populacional em função da sua participação na economia exportadora, pois nesse período, o Estado passava pelo ciclo do café, tornando o Porto de Paranaguá o maior exportador de café do país. Essa condição de pólo de atração permaneceu nos anos 70, em função da exportação de soja e trigo (PARANAGUÁ, 1994, p. 6).

$\mathrm{Na}$ dinâmica populacional de Paranaguá, além dos fluxos migratórios e do crescimento natural da população, existem as flutuações populacionais representadas pelas atividades ligadas ao Porto 
D. Pedro II, como os migrantes temporários, provenientes dos navios e caminhões. Também o turismo na época do verão traz para a cidade um incremento significativo no contingente populacional.

\section{METODOLOGIA}

Esta pesquisa aborda o espaço do perímetro urbano de Paranaguá numa perspectiva dinâmica, tomando por premissa 0 crescimento urbano como um processo que se manifesta em termos espaciais com dimensão temporal, cuja compreensão passada e atual conduz a estimar suas tendências futuras. Para tal, adotou-se a metodologia aplicada a estudos que se utilizam dos sistemas de informação geográfica (SIG), aliado ao sensoriamento remoto, visto que constituem técnicas imprescindíveis nos estudos ambientais, que levem em consideração as dinâmicas têmporo-espaciais.

Para a integração dos dados do sensoriamento remoto, ou seja, a preparação desses dados, para posterior integração com o SIG, recorreu-se nesta pesquisa aos métodos clássicos da fotointerpretação, associados à cartografia digital, para posterior análise espacial, no qual se utilizou o sistema de informação geográfica Idrisi. Em atendimento à metodologia utilizada nos sistemas de informações geográficas, foram realizadas as seguintes etapas de trabalho, que serão descritas a seguir:

\section{1) Fotointerpretação}

Inicialmente foi necessário construir uma modelagem com entidades espaciais, para o diagnóstico da dinâmica espacial da ocupação antrópica. Para realização dessa etapa de trabalho foram utilizadas fotografias aéreas pancromáticas, formato $23 \times 23 \mathrm{~cm}$, dos anos de: 1952, escala 1: 25.000, tomadas pelos Serviços Aerofotogramétricos Cruzeiro do Sul S.A.; 1962, escala 1: 70.000, tomadas pelo Instituto de Terras e Cartografia (ITC); 1980, escala 1:25.000, tomadas pela Aerosul S.A. e 1996, escala 1: 60.000, tomadas pela Aerosul S.A.

\section{2) Georreferenciamento das fotografias aéreas}

Com o objetivo de construir um mosaico digital e posteriormente um mapa base digital, foram escolhidas as fotografias aéreas pancromáticas do ano de 1996, por abrangerem a área total da pesquisa em três fotos e serem as mais recentes. Estas foram rasterizadas via Scanner, em 300 dpi (pontos por polegadas) no formato TIFF. 
Posteriormente, foram transferidas e convertidas para o formato exigido pelo Idrisi (.IMG), com o objetivo de serem georreferenciadas.

3) Construção do mosaico digital ou mosaicagem

Estando as fotos georreferenciadas, foi necessário uni-las para compor a área total da pesquisa: com três fotografias, sendo duas da faixa-07 de números 292 e 294 e uma da faixa-08 de número 331. Por meio das cartas foi possível identificar os limites de cada foto, em coordenadas do Sistema Universal Transverso de Mercator (UTM), de modo que unidas, por meio dos pontos de controle comuns entre si, formaram uma única imagem.

4) Interpretação do mosaico digital e digitalização dos planos de informação

Os planos de informação gerados nesta etapa foram: o primeiro plano de informação criado foi definido como Perímetro e digitalizado via display do computador, sobre o mosaico; o segundo plano de informação Tipos de Cobertura Vegetal para o ano de 1996, foi obtido por meio da interpretação e digitalização via display do computador e o terceiro plano de informação foi o denominado de Categorias de Uso da Terra para o ano de 1996. Terminado o plano Tipos de Cobertura Vegetal referente ao ano de 1996, iniciou-se a digitalização dos planos dos anos de 1980, 1962 e 1952.

5) Manipulações, cruzamentos e análises espaciais

Uma vez preparada a base de dados descrita acima, foi possível realizar as análises espaciais, por meio da ferramenta SIG do sofware Idrisi.

Para obter a dinâmica espacial da ocupação antrópica no perímetro urbano de Paranaguá, tomou-se inicialmente os planos referentes aos Tipos de Cobertura Vegetal 1952, 1962, 1980 e 1996. Como estes possuíam várias categorias de legenda (sete nos planos de 1952 e 1962, e oito nos de 1980 e 1996) e o cruzamento de todas estas resultaria numa quantidade muito grande de novas categorias, dificultando a análise dessa dinâmica espacial, optou-se então por dividir a informação em dois níveis: áreas com cobertura vegetal e áreas antropizadas, para toda a série temporal. Este procedimento resultou em quatro planos categorizados nos níveis citados anteriormente (1952, 1962, 1980 e 1996). No software Idrisi estes quatro planos de informação ficaram com três categorias de legenda: 0 - vazio (polígono externo ao perímetro urbano); 1 - outros; e 2 - áreas antropizadas. 
A etapa seguinte constituiu o cruzamento destes planos, sempre dois a dois. Tomou-se, em primeiro lugar, o plano de informação de 1952 e cruzou-se com o de 1962, resultando num terceiro plano denominado áreas antropizadas 1952 X 1962, apareceram algumas inconsistência nos dados, sendo necessária a reamostragem desse terceiro plano. Esse plano foi cruzado com o plano de informação do ano de 1980, o plano resultante, ou seja, áreas antropizadas 1952 X 1962 X 1980, também necessitou do procedimento de reamostragem. O último cruzamento foi desse, com o plano de 1996. Inconsistências nos dados também apareceram aqui, foram corrigidas gerando o mapa denominado de Dinâmica Espacial da Ocupação Antrópica no Perímetro Urbano de Paranaguá 1952 - 1996. Esse mapa originalmente está na escala 1: 50.000 (CANEPARO, 1999, p. 279).

A partir daí foram realizadas as medições e análises sobre os planos de informação, também foi possível estabelecer correlações, levando-se em consideração as observações de campo e o levantamento bibliográfico. Esses procedimentos permitiram a construção de uma modelagem para estudar a dinâmica espacial da ocupação antrópica no perímetro urbano de Paranaguá, bem como avaliar as tendências dessa dinâmica sobre esse perímetro.

\section{RESULTADOS E DISCUSSÕES}

O mapa 1 representa a Dinâmica Espacial da Ocupação Antrópica no Perímetro Urbano de Paranaguá 1952-1996, resultou em 6 categorias de legenda, em que a letra "A", corresponde às áreas antropizadas, "V", a áreas com cobertura vegetal e "v", área vazia, ou seja, corresponde à região aterrada do porto no período de 1962 a 1980. Estas letras são acrescidas do ano de sua ocorrência, visto que o objetivo do mapa é verificar a dinâmica de áreas antropizadas e vegetadas, no período de 1952 a 1996.

De um modo geral, este mapa mostra que a antropização sobre o perímetro urbano de Paranaguá se expandiu em quatro direções principais: nos manguezais das margens dos rios Emboguaçu e Itiberê, para sudoeste em direção a PR-407, ao longo dessa mesma estrada e entre os rios Emboguaçu-Mirim e Emboguaçu. Observou-se que a expansão urbana sobre a ilha dos Valadares, configurou-se como uma extensão da cidade de Paranaguá, em razão da sua proximidade com o centro da mesma. 
O quadro 1 sintetiza em hectares e percentagens a dinâmica espacial da ocupação antrópica no perímetro urbano de Paranaguá, no período de 1952 a 1996, bem como as respectivas categorias de uso da terra. Nesse quadro as categorias resultantes dos cruzamentos foram reagrupadas nos três períodos estudados: 1952-1962, 1962-1980 e 1980-1996, utilizando o critério da antropização sobre as áreas vegetadas.

\section{MAPA 1 - DINÂMICA ESPACIAL DA OCUPAÇÃO ANTRÓPICA NO PERÍMETRO} URBANO DE PARANAGUÁ - $1952-1996$

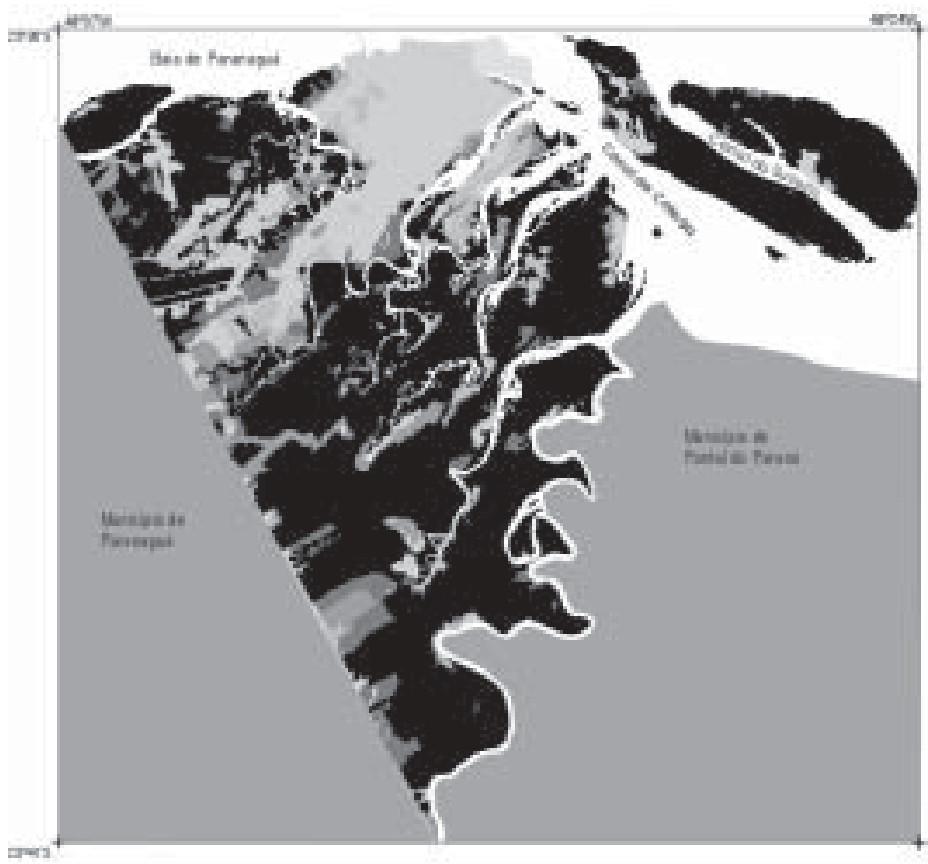

\section{LEGEEDS}

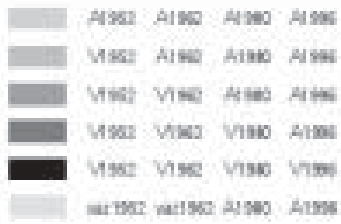


No período compreendido entre 1952 e 1962, foram antropizados 670 hectares no perímetro urbano de Paranaguá, representado pela categoria espacial V1952A1962A1980A1996. Essa categoria localizase, predominantemente, a oeste e sudoeste do núcleo urbano e na ilha dos Valadares.

A expansão antrópica ocorrida na cidade de Paranaguá entre 1952-1962 relacionou-se, em grande parte, ao ciclo café, que atraiu populações tanto de áreas rurais como de outros lugares. Este ciclo demandou a implementação de uma infra-estrutura urbana eficiente, que atendesse às necessidades das populações que para aí vieram, daí o adensamento de arruamentos na porção central da cidade. Muitos desses migrantes, com baixo poder aquisitivo, em busca de trabalho, ocuparam novos espaços, situados na periferia do centro histórico, em áreas de manguezais, nas imediações do porto, bem como nas áreas mais distantes, a sudoeste da cidade de Paranaguá.

$\mathrm{Na}$ ilha dos Valadares, essa época corresponde ao seu maior período de antropização, devido principalmente a sua proximidade com o centro da cidade de Paranaguá. Pode-se dizer também que a população ocupou esta ilha pelo baixo valor imobiliário, dada a inexistência de uma ponte de ligação com a cidade.

No período compreendido entre 1962 e 1980, foram antropizados 760 hectares no perímetro urbano de Paranaguá, representado pela categoria espacial: V1952V1962A1980A1996. Esta localiza-se, de uma maneira geral, ao longo de todo o perímetro urbano, principalmente a oeste e sudoeste da cidade, nas proximidades de ambas as margens do rio Emboguaçu e ao longo da PR-407. Também nas ilhas da Cotinga e Rasa da Cotinga.

A expansão antrópica ocorrida na cidade de Paranaguá, neste período, foi decorrente da crise do café, pois o local de beneficiamento passou de Paranaguá para as áreas produtoras e ocorreu também a queda do preço no mercado internacional. A cidade continuava atraindo populações, tanto de áreas rurais como de outros lugares. Neste período também iniciou-se a substituição do café pela soja e trigo, que favoreceu a instalação de empresas ligadas à exportação de grãos, na região próxima ao porto, todavia essas empresas, na sua maioria eram mecanizadas, portanto dispensadoras de mão-de-obra, pois os empregos disponíveis exigiam qualificação. Essa exportação motivou a ampliação do porto com um aterro. Estes fatos contribuíram para a redução na oferta de empregos, refletindo-se numa ocupação desordenada do espaço, principalmente nas áreas de manguezais 
próximas ao porto e em áreas mais distantes do núcleo urbano, portanto, menos valorizadas.

QUADRO 1 - DINÂMICA ESPACIAL DA OCUPAÇÃO ANTRÓPICA E CATEGORIAS DE USO DA TERRANO PERÍMETRO URBANO DE PARANAGUÁ

\begin{tabular}{|c|c|c|c|}
\hline $\begin{array}{l}\text { Dinâmica Espacial da } \\
\text { Ocupação Antrópica }\end{array}$ & $\begin{array}{l}\text { Área } \\
\text { (ha) }\end{array}$ & $\%$ & Categorias de uso da terra \\
\hline A1952A1962A1980A1996 & 2.297 & 16,10 & $\begin{array}{l}\text { Residencial, Portuária, Mercado } \\
\text { Municipal/Clube, Industrial, } \\
\text { RFFSA/Aeroporto, Mineração, PR- } \\
407 \text { - Comercial/ Residencial, } \\
\text { Loteamento, Chácaras/Śtios, } \\
\text { Pastagem, Desmatada/Aterrada }\end{array}$ \\
\hline V1952A1962A1980A1996 & 670 & 4,70 & $\begin{array}{l}\text { Residencial, Portuária, Mercado } \\
\text { Municipal/Clube, Industrial, } \\
\text { RFFSA/Aeroporto, Depósito de } \\
\text { lixo, Mineração, PR-407 - } \\
\text { Comercial/ Residencial, } \\
\text { Loteamento, Chácaras/Sítios, } \\
\text { Pastagem, Desmatada/Aterrada }\end{array}$ \\
\hline V1952V1962A1980A1996 & 760 & 5,33 & $\begin{array}{l}\text { Residencial, Mercado } \\
\text { Municipal/Clube, Industrial, RFFSA/ } \\
\text { Aeroporto, Mineração, PR-407 - } \\
\text { Comercial/ Residencial, } \\
\text { Loteamento, Chácaras/Sítios, } \\
\text { Pastagem, Desmatada/Aterrada }\end{array}$ \\
\hline V1952V1962V1980A1996 & 839 & 5,88 & $\begin{array}{l}\text { Residencial, Portuária, Mercado } \\
\text { Municipal/Clube, Industrial, } \\
\text { Depósito de lixo, Mineração, PR- } \\
407 \text { - Comercial/Residencial, } \\
\text { Loteamento, Chácaras /Sítios, } \\
\text { Pastagem, Desmatada/Aterrada }\end{array}$ \\
\hline V1952V1962V1980V1996 & 9595 & 67,24 & Cobertura vegetal preservada \\
\hline v1952v1962A1980A1996 & 108 & 0,75 & Portuária, Desmatada/Aterrada \\
\hline TOTAL & 14269 & 100 & \\
\hline
\end{tabular}

FONTE: Mapa da Dinâmica Espacial da Ocupação Antrópica no Perímetro Urbano de Paranaguá 1952 - 1996 (mapa 1) e Plano de Informação Categorias de Uso da Terra no Perímetro Urbano de Paranaguá - 1996.

A ocupação ao longo da PR-407 ocorreu em função do desenvolvimento comercial, voltado ao turismo, da abertura de loteamentos e de estradas secundárias em direção às chácaras e sítios. 
No período compreendido entre 1980 e 1996, foram antropizados 839 hectares no perímetro urbano de Paranaguá, representado pela categoria espacial: V1952V1962V1980A1996. Essa categoria localizase em todo o perímetro urbano, sendo que na área da cidade situa-se predominantemente nos manguezais e nos remanescentes da restinga. Também estão presentes a sudoeste da cidade, nas proximidades do Emboguaçu, em direção ao limite do perímetro urbano e nas proximidades da margem esquerda do rio Pequeno.

A modernização portuária, em função principalmente da soja e trigo, promoveu uma desvinculação dos empregos ligados a este setor, o qual dispensou mão-de-obra desqualificada, resultando na diminuição do poder aquisitivo da população. Este fato refletiu-se na ocupação de espaços, mais distantes do centro urbano, ou seja, em áreas menos valorizadas, bem como no avanço da ocupação de áreas insalubres, como os manguezais.

Outro fator que acelerou a expansão antrópica foi a implantação de empresas, ligadas ao setor portuário e na região sudoeste da cidade. A estrada de ligação da BR-277 ao porto e a construção da ponte sobre o rio Emboguaçu promoveram a abertura de novas áreas de expansão, bem como o adensamento de áreas já ocupadas. A construção da ponte sobre o rio Itiberê, facilitando o acesso à ilha dos Valadares, inaugurada em 1990, proporcionou um adensamento das áreas já ocupadas. Dessa maneira, os remanescentes dos manguezais localizados nas imediações do centro urbano desapareceram.

As três categorias restantes pertencem às áreas que sempre permaneceram antropizadas (A1952A1962A1980A1996), às áreas ainda vegetadas do perímetro urbano (V1952V1962V1980V1996) e à área que corresponde ao aterro do Porto D. Pedro II (v1952v1962A1980A1980).

\section{CONCLUSÕES}

Pode-se afirmar que todas as perdas ocorridas nos tipos de cobertura vegetal estão associadas à antropização. Na área de estudo, a vegetação foi devastada em função da expansão urbana: construção de residências, indústrias, mercado, clube, aeroporto, estrada de ferro (RFFSA), bem como expansão portuária. Nos locais mais distantes do núcleo urbano, essa redução deu-se em função da abertura de estradas, 
loteamentos e implantação de áreas rurais. No caso da PR- 407, aí mesclam-se residências e áreas comerciais.

$\mathrm{Na}$ década de 1950, quando finalizou-se o ciclo da madeira, as maiores concentrações de ruas, na cidade de Paranaguá, ocorreram no Centro Histórico e suas imediações e em direção ao Porto D. Pedro II, evidenciando a estreita relação entre a configuração espacial da cidade e o porto.

Conclui-se que, nos períodos anteriores a 1952, os ciclos econômicos foram responsáveis diretos pelas transformações e modificações espaciais, ou seja, pela dinâmica espacial da cidade de Paranaguá e suas imediações. Também promoveram a devastação de áreas de manguezais, localizados predominantemente nas margens do rio Itiberê (Centro Histórico) e na baía de Paranaguá, com a construção do porto.

Quanto à dinâmica espacial da ocupação antrópica no perímetro urbano de Paranaguá, no período estabelecido para esta pesquisa (1952-1996), os cruzamentos via sistema de informação geográfica resultaram em dezessete categorias, o que comprova uma forte dinâmica espacial ao longo do período estudado. Esta é resultante do processo histórico, aliado às dinâmicas sociais e econômicas ocorridas durante e anteriormente ao período estudado.

De um modo geral, conclui-se que as tendências de ocupação do espaço no perímetro urbano de Paranaguá estão vinculadas aos seguintes fatores: aos ciclos econômicos do setor portuário, à migração, ao crescimento natural da população e ao acesso às praias.

A utilização do sensoriamento remoto, aliado ao sistema de informação geográfica no estudo da expansão de áreas urbanas, permitiu avaliar com precisão a dinâmica da ocupação antrópica, tanto em nível espacial como temporal, consolidando-se como metodologias imprescindíveis ao planejamento. O sistema de informação geográfica através da construção de planos de informação possibilitou a compreensão de características físicas e humanas do espaço estudado. A partir de manipulações e cruzamentos realizados sobre os planos de informação, foi possível elaborar análises espaciais e estabelecer correlações com os aspectos demográficos, históricos e econômicos, possibilitando a compreensão da dinâmica espacial da ocupação antrópica sobre o perímetro urbano como um todo, bem como sobre áreas isoladas. Também é importante ressaltar que os arquivos digitais possibilitam a atualização dos planos de informação a qualquer momento. 


\section{REFERÊNCIAS}

ANGULO, R. Geologia da planície costeira do Estado do Paraná. São Paulo, 1992. 334 p. Tese (Doutorado em Geologia) - Instituto de Geociências, Universidade de São Paulo.

BIGARELLA, J. J. et al. A serra do mar e a porção oriental do estado do Paraná. Curitiba: Associação de Defesa e Educação Ambiental, 1978. $248 \mathrm{p}$.

BURROUGH, P. A. Principles of geographical information systems for land resources asseement. Oxford: Clarendon Press, 1989. 194 p.

CANEPARO, S. C. Manguezais de Paranaguá: uma análise da dinâmica espacial da ocupação antrópica - 1952-1996. Curitiba, 1999. 289 p. Tese (Doutorado em Meio Ambiente e Desenvolvimento) - Universidade Federal do Paraná.

COSTA, L. J. M. et al. Diagnóstico socioambiental da cidade de Paranaguá -1995. Curitiba: Universidade Federal do Paraná, 1999. $47 \mathrm{p}$.

EASTMAN, J. R. Manual do usuário - Idrisi for windows versão 2. Porto Alegre: UFRGS, 1998. $240 \mathrm{p}$.

EMBRAPA. Levantamento de reconhecimento do solos do Estado do Paraná. Londrina, 1984. 2 v. (Boletim de pesquisa, n. 27 e Boletim técnico, n. 16).

GODOY, A. M. G. Os impactos socioambientais na expansão do porto de Paranaguá frente à maior inserção do Brasil no mercado internacional. In: MEIO ambiente e desenvolvimento no litoral do Paraná: diagnóstico. Curitiba: UFPR, 1998. p. 231-235.

- Um olhar sobre a cidade de Paranaguá: os impactos socioambientais das mudanças portuárias. Curitiba, 1998. 230 p. Tese (Doutorado em Meio Ambiente e Desenvolvimento) - Universidade Federal do Paraná.

IAPAR. Cartas climáticas do Estado do Paraná. Londrina, 1994. 45 p. 
IBGE. Censo demográfico dados distritais Paraná. Rio de Janeiro, 1982. 26-27 (IX Recenseamento geral do Brasil - 1980, v. 1, t. 3, n. 18, Estado do Paraná).

. Censo demográfico de 1960. Rio de Janeiro, 1960. 197 p. (Série regional, v. 1, t. 14, Estado do Paraná).

. Censo demográfico de 1991. Rio de Janeiro, 1991. 586 p. (n. 22, Estado do Paraná).

. Censo demográfico Paraná. Rio de Janeiro, 1970. 320 p. (Série regional, v. 1, t. 19).

. Censos demográficos e econômicos. Rio de Janeiro, 1955. 496 p. (Série regional, v. 26, Estado do Paraná).

. Contagem da população - 1996. Rio de Janeiro, 1997. v. 1, $723 \mathrm{p}$. $92 \mathrm{p}$.

. Manual técnico da vegetação brasileira. Rio de Janeiro, 1992.

MAACK, R. Geografia física do Estado do Paraná. Curitiba: Banco de Desenvolvimento do Paraná, 1968. 350 p.

MORGENSTERN, A. Porto de Paranaguá contribuição à história período: 1648 / 1935. Paranaguá: Administração dos Portos de Paranaguá e Antonina, 1985. 139 p.

OKA-FIORI, C.; CANALI, N. E. Mapeamento geomorfológico. In: MEIO ambiente e desenvolvimento no litoral do Paraná: diagnóstico. Curitiba: UFPR, 1998. p. 51-56.

PARANAGUÁ. Secretaria de Transportes. Administração dos Portos de Paranaguá e Antonina. Porto de Paranaguá. Paranaguá, 1994. $114 \mathrm{p}$.

RIVERAU, J. C.; FUCK, R. A.; MURATORI, A. et al. Paranaguá, folha geológica. Curitiba: Comissão da Carta Geológica do Paraná, 1969. 1 mapa; color.; 64 x $46 \mathrm{~cm}$. Escala 1:70.000 
RODERJAN, C. V.; KUNIYOSHI, Y. S. Macrozoneamento florístico da área de proteção ambiental APA - Guaraqueçaba. Curitiba: Fundação de Pesquisas Florestais do Paraná, 1988. 53 p.

SANTOS, A. V. Memória histórica da cidade de Paranaguá e seu município. 3. ed. Paranaguá: Câmara Municipal, 1952. v. 1.

TRAMUJAS, A. Histórias de Paranaguá - dos pioneiros da Cotinga à porta do Mercosul no Brasil Meridional. Paranaguá: Prefeitura Municipal de Paranaguá, 1996. 180 p. 